Subscriber access provided by Caltech Library

\title{
Communication
}

\section{A Mixed-Valence Superstructure Assembled from A Mixed-Valence Host-Guest Complex}

Zhichang Liu, Marco Frasconi, Wei-Guang Liu, Yu Zhang, Scott M. Dyar, Dengke Shen, Amy A. Sarjeant, William A. Goddard, Michael R. Wasielewski, and J. Fraser Stoddart

J. Am. Chem. Soc., Just Accepted Manuscript • DOI: 10.1021/jacs.8b05322 • Publication Date (Web): 27 Jun 2018

Downloaded from http://pubs.acs.org on June 27, 2018

\section{Just Accepted}

"Just Accepted" manuscripts have been peer-reviewed and accepted for publication. They are posted online prior to technical editing, formatting for publication and author proofing. The American Chemical Society provides "Just Accepted" as a service to the research community to expedite the dissemination of scientific material as soon as possible after acceptance. "Just Accepted" manuscripts appear in full in PDF format accompanied by an HTML abstract. "Just Accepted" manuscripts have been fully peer reviewed, but should not be considered the official version of record. They are citable by the Digital Object Identifier (DOI®). "Just Accepted" is an optional service offered to authors. Therefore, the "Just Accepted" Web site may not include all articles that will be published in the journal. After a manuscript is technically edited and formatted, it will be removed from the "Just Accepted" Web site and published as an ASAP article. Note that technical editing may introduce minor changes to the manuscript text and/or graphics which could affect content, and all legal disclaimers and ethical guidelines that apply to the journal pertain. ACS cannot be held responsible for errors or consequences arising from the use of information contained in these "Just Accepted" manuscripts. 
Long-range electron delocalization ${ }^{1}$ involving noncovalently bonded assemblies plays a pivotal role in biological processes such as light-harvesting antenna complexes ${ }^{2}$. A steadily improving understanding of electron delocalization at the molecular level has been assisted by the investigation of artificial model systems - involving donor-acceptor assemblies ${ }^{3-5}$ and mixed-valence complexes $^{6-8}$ - which have instigated the creation of optoelectronic devices. Indeed, tremendous advances have been made ${ }^{7,9}$ towards developing artificial systems composed of molecular frameworks and supramolecular architectures. The development of host-guest chemistry has opened ${ }^{10-11}$ the door to synthetic hosts being ideal systems for studying electron delocalization through noncovalent-bonding interactions. Since the late 1980s, we have investigated $^{12}$ cyclobis(paraquat- $p$-phenylene) $\left(\mathrm{CBPQT}^{4+}\right.$, Figure 1a)-composed of two 1,1'-dialkyl-4,4'-bipyridinium $\left(\mathrm{BIPY}^{2+}\right.$, Figure 1a) dicationic units - which is capable of forming inclusion complexes with neutral $\pi$-electron-rich guests through $\pi-\pi$ and charge-transfer interactions. Recently, we discovered ${ }^{13}$ the ability of $\mathrm{CBPQT}^{4+}$, when reduced to $\mathrm{CBPQT}^{2(\cdot)}$, to form a stable $1: 1$ inclusion complex $\mathrm{BIPY}^{*+} \subset \mathrm{CBPQT}^{2(+)}$ with appropriate guests containing BIPY ${ }^{*+}$ because of favorable radical-radical interactions $^{14-16}$. By employing this $1: 1$ complex as a template,

\begin{abstract}
Herein, we report an unprecedented mixedvalence crystal superstructure which consists of a 2:1 host-guest cyclobis(paraquat- $p$-phenylene) $]$. One electron is distributed sta-
(n) tistically between three $\left[\mathrm{MV} \subset(\mathrm{CBPQT})_{2}\right]^{++}$comprised of a total
of 15 viologen units. The mixed-valence state is validated by single-crystal X-ray crystallography which supports an empirical formula of $\left[\mathrm{MV} \subset(\mathrm{CBPQT})_{2}\right]_{3} \cdot\left(\mathrm{PF}_{6}\right)_{2}$ for the body-centered cubic evidence of electron delocalization. Quantum chemistry calculations confirm the mixed-valence state in the crystal superstructure.
Our findings demonstrate that precise tuning of the redox states in host-guest systems can lead to a promising supramolecular strategy for achieving long-range electron delocalization in solid-state devices.
\end{abstract}

many high-energy mechanically interlocked molecules ${ }^{17-}$ ${ }^{18}$ (MIMs) - which would otherwise be difficult to synthesizehave been prepared. These MIMs exhibit intramolecular electron delocalization in their mixed-valence states thanks to the protection of the mechanical bond.

Herein, we demonstrate an unprecedented example of mixedvalence states in a crystal superstructure assembled from a unique 2:1 host-guest complex $\mathrm{MV} \subset(\mathrm{CBPQT})_{2}$ ( $\mathrm{MV} \equiv$ methyl viologen) — namely, one MV entity encircled by two CBPQT ringswhich bears evenly $2 / 3+$ charge. In other words, two positive charges are distributed statistically among total 15 BIPY units assembled into two $\mathrm{MV}^{\circ+} \subset\left(\mathrm{CBPQT}^{0}\right)_{2}$ and one neutral $\mathrm{MV}^{0} \subset\left(\mathrm{CBPQT}^{0}\right)_{2}$. The formation of this mixed-valence complex as well as its unusual ratio of BIPY/charge have been confirmed by single-crystal $\mathrm{X}$-ray diffraction (XRD), which affords an empirical formula of $\left[\mathrm{MV} \subset(\mathrm{CBPQT})_{2}\right]_{3} \cdot\left(\mathrm{PF}_{6}\right)_{2}$ for the body-centered cubic superstructure, while the existence of free radicals in the bulk sample has been proved by electron paramagnetic resonance (EPR) spectroscopy. Quantum chemistry calculations support the existence of mixed-valence state.

a

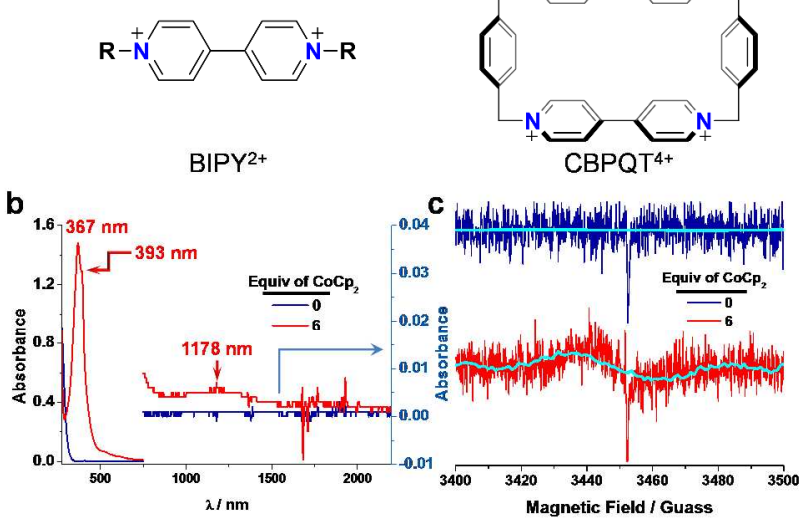

Figure 1. (a) Structural formulas of $\mathrm{BIPY}^{2+}$ and $\mathrm{CBPQT}^{4+}$. (b) UV-Vis-NIR Absorption and (c) EPR spectra of an equimolar mixture (deep blue) of $\mathrm{CBPQT} 4 \mathrm{PF}_{6}$ and $\mathrm{MV} \cdot 2 \mathrm{PF}_{6}$ and its reduced product (red) upon addition of 6 equiv of $\mathrm{CoCp}_{2}$. 
To understand the binding properties ${ }^{19}$ of $\mathrm{CBPQT}^{0}$ towards neutral $\mathrm{MV}^{0}$, we investigated the reduction of an equimolar mixture of $\mathrm{CBPQT} \cdot 4 \mathrm{PF}_{6}$ and $\mathrm{MV} \cdot 2 \mathrm{PF}_{6}$ using cobaltocene $\left(\mathrm{CoCp} \mathrm{p}_{2}\right)$. The UV-Vis-NIR spectrum (Figure 1b) of this mixture before reduction exhibits no Vis-NIR absorption bands and no EPR signals are observed (Figure 1c). Upon reducing this mixture with 6 equiv of $\mathrm{CoCp}_{2}$, a new band appears at $367 \mathrm{~nm}$ with a shoulder at $392 \mathrm{~nm}$, observations which are in line with the spectra reported ${ }^{19-}$ ${ }^{20}$ for neutral $\mathrm{CBPQT}^{0}$ and $\mathrm{MV}^{0}$, indicating the generation of both these neutral forms. We observed, however, a very weak broad NIR absorption band at $\sim 1178 \mathrm{~nm}$, which is not really noticeable until it is magnified 20-fold. This characteristic NIR band, which de-rives from charge-resonance transitions, can be ascribed to the formation of complexes between BIPY ${ }^{0}$ and trace of the incompletely reduced $\mathrm{BIPY}^{*+}$ radical cations. Consistent with the appearance of the NIR band, a non-negligible weak EPR signal is also evident for the reduced solution sample, confirming the presence of radical species. The existence of both weak NIR band and EPR signal indicates that, although most of this mixture is reduced to $\mathrm{CBPQT}^{0}$ and $\mathrm{MV}^{0}$, trace amounts of BIPY in CBPQT or MV still remain as radical cationic $\mathrm{BIPY}^{\circ+}$ which associates with its neutral counterpart BIPY ${ }^{0}$. Thus, certain mixed-valence complexes are formed.

This observation encouraged us to assess the formation of complexes in the extreme case of a mixed-valence system. Despite the rapid disproportionation of $\mathrm{BIPY}^{\circ+}$ radical cations, we were able to obtain black single crystals suitable for XRD from an equimolar mixture of $\mathrm{CBPQT} \cdot 4 \mathrm{PF}_{6}$ and $\mathrm{MV} \cdot 2 \mathrm{PF}_{6}$ reduced with 6 equiv of $\mathrm{CoCp}_{2}$. The resulting black crystals are strikingly different from the red crystals of $\mathrm{CBPQT}^{0}$ and $\mathrm{MV}^{0}$. Single-crystal XRD analysis (Figure 2) shows that the superstructure is composed of a unique 2:1 host-guest complex $\mathrm{MV} \subset(\mathrm{CBPQT})_{2}$ - namely, a $\mathrm{MV}$ entity embraced by two CBPQT rings with a $\mathrm{C}_{2}$ axis passing perpendicularly (Figure 2c) through the center of the MV plane. Two isostructural CBPQT rings - adopting a slightly conical shape with two angles between the ring plane and two $p$-xylene planes of 100 and $104^{\circ}$ - are held (Figure $2 \mathrm{~b}$ ) together head-to-head by six $[\mathrm{H} \cdots \mathrm{H}]$ contacts of 2.33-2.39 $\AA$. The "corner" angles of CBPQT are $112^{\circ}$, a value which is comparable with the $113^{\circ}$ found in $\mathrm{CBPQT}^{0}$. The mean distance between two BIPY planes of CBPQT is $6.83 \AA$, similar to the value reported ${ }^{19}$ for $\mathrm{CBPQT}^{0}$. The MV entity is encapsulated through $\pi-\pi$ interactions of $3.31 \AA$ between MV and two CBPQT as well as by four $[\mathrm{C}-\mathrm{H} \cdots \pi]$ interactions of 2.85-2.94 $\AA$ with a dihedral angle between MV and CBPQT of $70^{\circ}$. Somewhat unexpectedly, the positive charge carried by this complex is observed to be a non-integer less than one-namely, $\left[\mathrm{MV} \subset(\mathrm{CBPQT})_{2}\right]^{2 / 3+}$-based on the average number of $\mathrm{PF}_{6}^{-}$associated with each complex, indicating that statistically every two positive charges are distributed over three $\mathrm{MV} \subset(\mathrm{CBPQT})_{2}$ complexes comprised of a total of 15 BIPY units. This $\left[\mathrm{MV} \subset(\mathrm{CBPQT})_{2}\right]^{2 / 3+}$ complex is unprecedented on account of the fact that there are no examples of (i) one aromatic guest encircled by two CBPQT rings and (ii) a host-guest complex bearing charges more than zero but less than one.

Despite the fact that torsional angles associated with BIPY change upon guest complexation, the change in the bond lengths can be used to establish ${ }^{19,21-22}$ the oxidation states of BIPY. To clarify the oxidation states of each BIPY of $\left[\mathrm{MV} \subset(\mathrm{CBPQT})_{2}\right]^{2 / 3+}$, we compared the bond lengths of two classes of BIPY units in this complex with those for BIPY reportedly ${ }^{19,23}$ present in $\mathrm{CBPQT}^{4+}$, $\mathrm{CBPQT}^{2(+)}$, and $\mathrm{CBPQT}^{0}$ as well as $\mathrm{MV}^{2+}, \mathrm{MV}^{*+}$, and $\mathrm{MV}^{0}$. We were able to identify (Figure 3 ) a clear trend in the lengths of the bonds in BIPY at different redox states. In particular, the bond length for $\mathrm{C} 4-\mathrm{C} 4$ ' undergoes a distinct change from $\sim 1.49 \AA(2+)$, to $\sim 1.43 \AA(\bullet+)$, to $\sim 1.37 \AA(0)$, in line with the nature of bond $\mathrm{C} 4-\mathrm{C} 4$ ' changing from a single bond, a radical-delocalized bond,
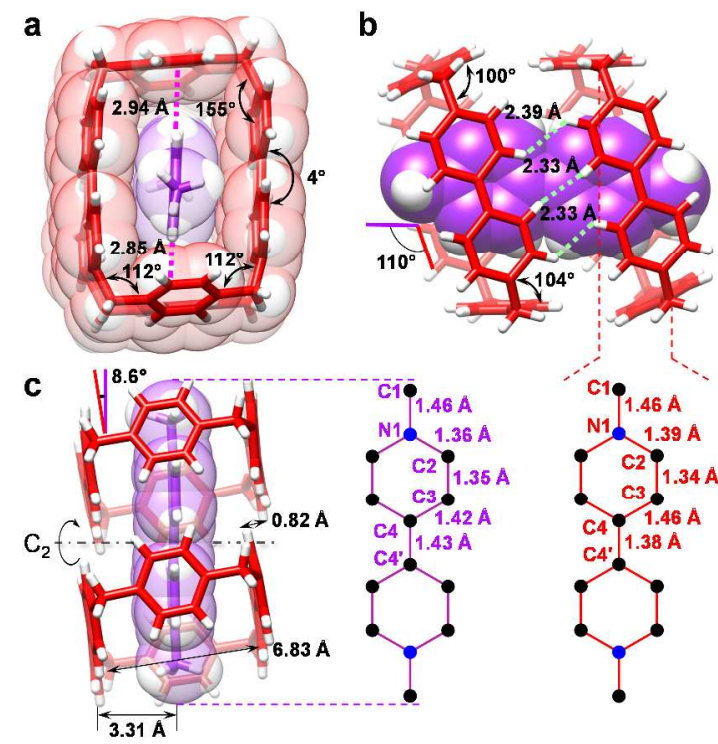

Figure 2. Crystal (super)structure of $\mathrm{MV} \subset(\mathrm{CBPQT})_{2}$. (a) Front view showing the corner angles of CBPQT, torsional angle of BIPY in CBPQT, and [C-H $\cdots \pi]$ interactions (pink dash lines). (b) Side view exhibiting the angles between xylene planes and CBPQT, the dihedral angle between MV and CBPQT, and [H $\cdots \mathrm{H}]$ interactions (blue dash lines) between two CBPQT. (c) Top view indicating the $\mathrm{C}_{2}$ symmetrical axis and the width of CBPQT, and $\pi-\pi$ interactions between MV and CBPQT. H, white; CBPQT, red; $\mathrm{MV}$, purple. The bond lengths of BIPY in MV and CBPQT are portrayed in purple and red, respectively.

to a double bond. Based on this regularity, we found that the bond lengths of BIPY for $\mathrm{CBPQT}$ in $\mathrm{MV} \subset(\mathrm{CBPQT})_{2}$ match well with those reported for $\mathrm{BIPY}$ of $\mathrm{CBPQT}^{0}$ and $\mathrm{MV}^{0}$, indicating that $\mathrm{CBPQT}$ in $\mathrm{MV} \subset(\mathrm{CBPQT})_{2}$ is in its neutral $\mathrm{CBPQT}^{0}$ state. On the other hand, the bond lengths for $\mathrm{MV}$ in $\mathrm{MV} \subset(\mathrm{CBPQT})_{2}$ are comparable with those of $\mathrm{BIPY}^{\cdot+}$ in $\mathrm{CBPQT}^{2(\cdot+)}$ and $\mathrm{MV}^{\cdot+}$, suggesting the radical cationic $\mathrm{MV}^{\circ+}$ state of $\mathrm{MV}$. Bond-length analysis indicate that most of $\mathrm{MV} \subset(\mathrm{CBPQT})_{2}$ are likely in their mixedvalence state $\mathrm{MV}^{*+} \subset\left(\mathrm{CBPQT}^{0}\right)_{2}$ on account of the formula of $\left[\mathrm{MV} \subset(\mathrm{CBPQT})_{2}\right]^{2 / 3+}$ of the complex.

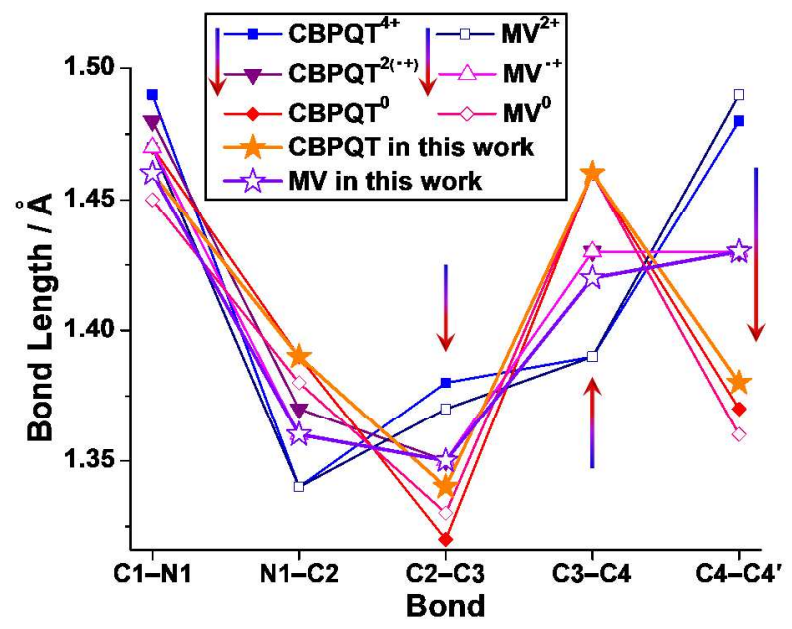

Figure 3. Comparison of bond lengths of BIPY in $M V$ and $\mathrm{CBPQT}$ for $\mathrm{MV} \subset(\mathrm{CBPQT})_{2}$ with $\mathrm{BIPY}$ in $\mathrm{CBPQT}^{4+}, \mathrm{CBPQT}^{2(+)}$, $\mathrm{CBPQT}^{0}, \mathrm{MV}^{2+}, \mathrm{MV}^{\circ+}$, and $\mathrm{MV}^{0}$. Arrows indicate the changes in bond lengths of BIPY.

The existence of the unpaired electrons in the mixed-valence crystals was also confirmed by EPR spectroscopy. An EPR signal inhomogeneously broadened by many hyperfine splittings was 

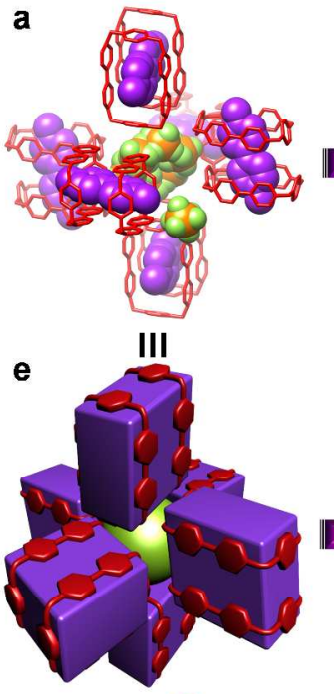

i

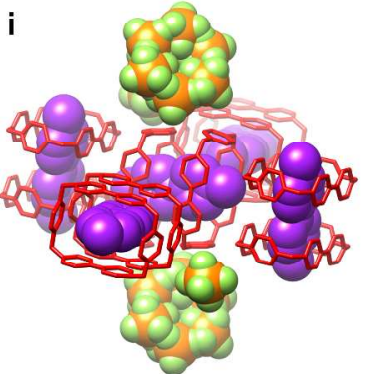

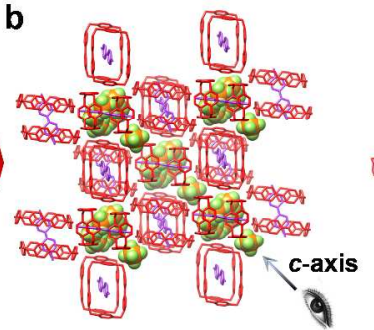

III

f

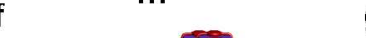

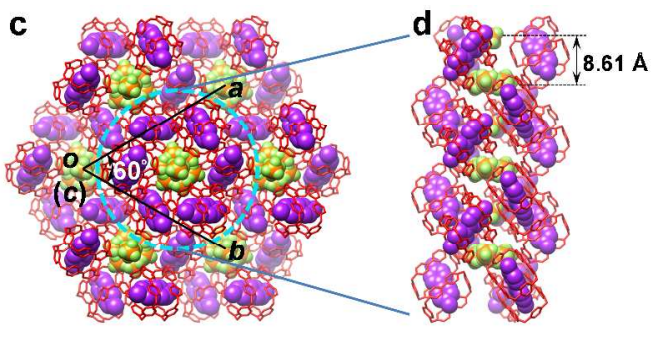

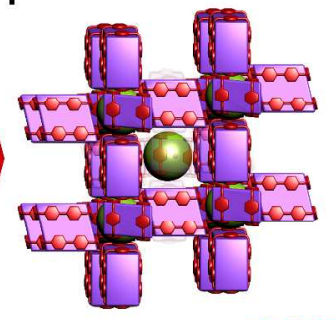

g
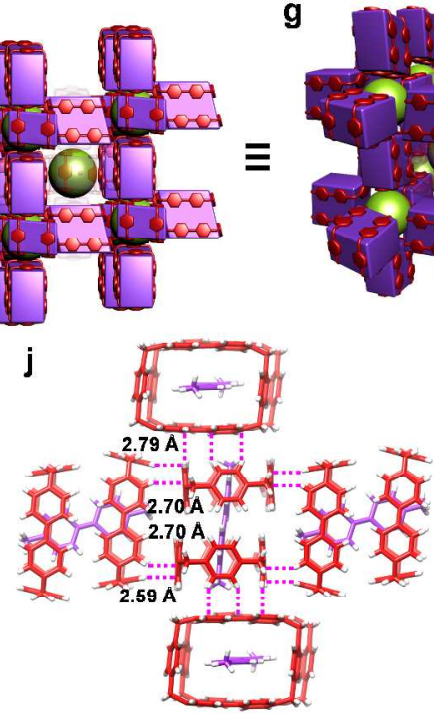

h
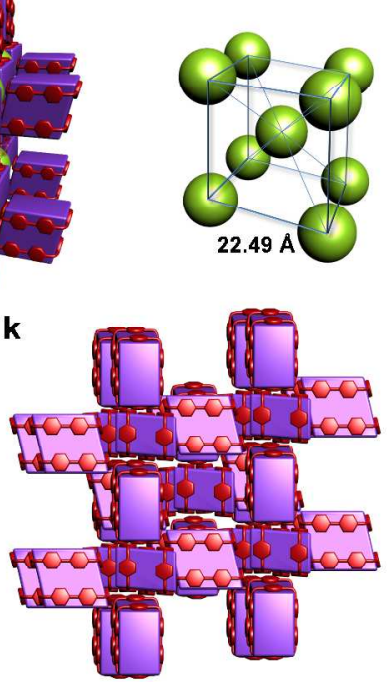

Figure 5. Crystal superstructure of $\left[\mathrm{MV} \subset(\mathrm{CBPQT})_{2}\right]_{3} \cdot\left(\mathrm{PF}_{6}\right)_{2}$. (a) Octahedron assembled from six $\mathrm{MV} \subset(\mathrm{CBPQT})_{2}$ surrounding two $\mathrm{PF}_{6}{ }_{6}^{-}$ and (e) its schematic representation. (b) Body-centered cubic superstructure assembled by adjacent octahedrons sharing $\mathrm{MV} \subset(\mathrm{CBPQT})_{2}$ as linkers and (f and g) its schematic representations. (d) Hexagonal channels packing into (c) hexagonal arrangement as viewing along $c$-axis (the diagonal of the cube in b). (h) Schematic representation of body-centered cubic superstructure after removing all MV $\subset(\mathrm{CBPQT})_{2}$. Green balls represent $\mathrm{PF}_{6}{ }^{-}$pairs in e-h. (i) A representation showing that every $\mathrm{MV} \subset(\mathrm{CBPQT})_{2}$ is encircled by four $\mathrm{MV} \subset(\mathrm{CBPQT})_{2}$ and two pairs of $\mathrm{PF}_{6}^{-}$. (j) 20 Complementary $[\mathrm{C}-\mathrm{H} \cdots \pi]$ interactions (Figure S2) of 2.59-2.79 $\AA$ between BIPY planes and $\mathrm{H}$ atoms on CBPQT of adjacent $\mathrm{MV} \subset(\mathrm{CBPQT})_{2}$. (k) Schematic representation of an extended body-centered cubic framework wherein $\mathrm{PF}_{6}{ }^{-}$pairs are omitted. CBPQT, red; MV, purple; F, green; $\mathrm{P}$, yellow. $\mathrm{H}$ atoms in a-d and $\mathrm{i}$ and solvents are omitted.

obtained (Figure 4 ) on a crystalline sample, and had $g$-factor similar to those reported ${ }^{19}$ for mixed-valence BIPY ${ }^{*+}$-containing solidstate samples, indicating the presence of free radicals in the solidstate superstructure. Since no single $\mathrm{MV} \subset(\mathrm{CBPQT})_{2}$ bears statistically one full positive charge based on the empirical formula of $\left[\mathrm{MV} \subset(\mathrm{CBPQT})_{2}\right]_{3} \cdot\left(\mathrm{PF}_{6}\right)_{2}$, we believe that the unpaired electron is delocalized inside $\left[\mathrm{MV} \subset(\mathrm{CBPQT})_{2}\right]^{+}$.

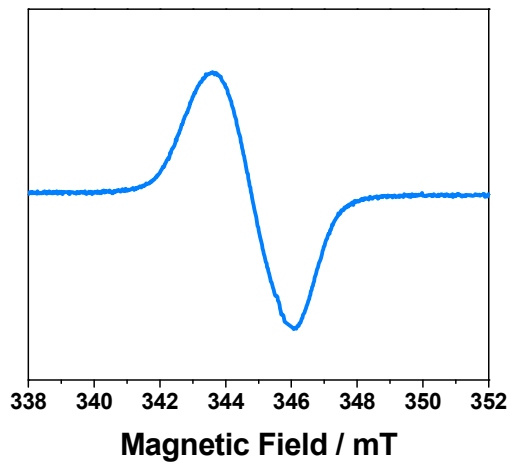

Figure 4. Solid-state continuous-wave EPR spectrum of crystals of $\left[\mathrm{MV} \subset(\mathrm{CBPQT})_{2}\right]_{3} \cdot\left(\mathrm{PF}_{6}\right)_{2}$.

The X-ray crystal superstructure reveals that every two $\mathrm{PF}_{6}{ }^{-}$anions - one of them disordered (Figure S1) about a six-fold $c$ axis-are surrounded by the para-xylylene planes of six $\mathrm{MV} \subset(\mathrm{CBPQT})_{2}$ to form (Figure $5 \mathrm{a}$ and $\mathrm{e}$ ) an octahedron wherein six $\mathrm{MV} \subset(\mathrm{CBPQT})_{2}$ occupy the vertices, but they also serve as shared linkers in connecting these octahedrons together in a threedimensional array which extends throughout the whole crystal. Thus, every octahedron has the empirical formula of $\left[\mathrm{MV} \subset(\mathrm{CBPQT})_{2}\right]_{3} \cdot\left(\mathrm{PF}_{6}\right)_{2}$. The $\left[\mathrm{MV} \subset(\mathrm{CBPQT})_{2}\right]_{3} \cdot\left(\mathrm{PF}_{6}\right)_{2}$ repeating motifs adopt (Figure 5b, f-g) an approximately body-centered cubic packing arrangement, wherein (i) $\mathrm{PF}_{6}{ }^{-}$anion pairs represent (Figure 5h) the vertices and the center of the cube and (ii) each $\mathrm{MV} \subset(\mathrm{CBPQT})_{2}$ is linked with two pairs of $\mathrm{PF}_{6}{ }^{-}$through its two outward-pointing para-xylylene faces. As viewed along the $c$-axis (Figure 5b), hexagonal channels - which are filled (Figure 5d) up with $\mathrm{PF}_{6}{ }^{-}$anions at $8.61 \AA$ apart from each other and penetrate through every octahedron - can be observed to pack (Figures 4c and S1) into a hexagonal arrangement. In the superstructure every $\mathrm{MV} \subset(\mathrm{CBPQT})_{2}$ is encircled (Figure 5i) by four adjacent $\mathrm{MV} \subset(\mathrm{CBPQT})_{2}$ and two pairs of $\mathrm{PF}_{6}^{-}$generating an octahedron. Since every complex has three types of facets - namely, paraxylylene planes, BIPY planes, and CBPQT ring planes - in which the para-xylylene planes interact with $\mathrm{PF}_{6}{ }^{-}$anions, every $\mathrm{MV} \subset(\mathrm{CBPQT})_{2}$ links (Figures $5 \mathrm{j}$ and $\mathrm{S} 2$ ) with four adjacent but orthogonally oriented $\mathrm{MV} \subset(\mathrm{CBPQT})_{2}$ by means of 20 complementary $[\mathrm{C}-\mathrm{H} \cdots \pi]$ interactions ranging from 2.59 to $2.79 \AA$ between the BIPY planes and $\mathrm{H}$ atoms on the CBPQT rings, assembling (Figure 5k) into an extended body-centered cubic framework with $\mathrm{PF}_{6}^{-}$pairs as vertices and center of each cube. Hirshfeld surface analysis confirms ${ }^{24}$ (Figure S2b) that the reciprocal $[\mathrm{C}-\mathrm{H} \cdots \pi] /[\pi \cdots \mathrm{H}-\mathrm{C}]$ interactions, which contribute $79.8 \%$, are the most significant interactions between $\mathrm{MV} \subset(\mathrm{CBPQT})_{2}$ 
units. This extended superstructure can be a result of the even distribution of the positive charges throughout the whole crystal.

Quantum chemistry calculations were carried out to analyze the charge distribution within and beyond $\mathrm{MV} \subset(\mathrm{CBPQT})_{2}$ in the solid state. The optimized unit cell contains (Figure S3) three $\mathrm{MV} \subset(\mathrm{CBPQT})_{2}$ (a, b and $\left.\mathbf{c}\right)$ and two $\mathrm{PF}_{6}^{-}$. Mulliken-charge and spin-population analyses of both $\mathrm{MV} \subset(\mathrm{CBPQT})_{2}$ and $\mathrm{MV}$ show (Table S2) that the two positive charges are not evenly distributed in the three $\mathrm{MV} \subset(\mathrm{CBPQT})_{2}$ but are localized on two $\mathrm{MV}^{\cdot+} \subset\left(\mathrm{CBPQT}^{0}\right)_{2}$ with one neutral $\mathrm{MV}^{0} \subset\left(\mathrm{CBPQT}^{0}\right)_{2}$. The calculated bond lengths (Table S2) for $\mathrm{C}^{-}-\mathrm{C}^{\prime}$ ' in $\mathrm{MV}^{0}(1.36 \AA)$ and $\mathrm{MV}^{\bullet+}(1.42 \AA)$ agree well with the trend in Figure 3. The uneven distribution of positive charge attracts $\mathrm{PF}_{6}^{-}$anions, encouraging one of them to drift from the 3-fold axis to a position that is closer to the two $\mathrm{MV}^{\bullet+} \subset\left(\mathrm{CBPQT}^{0}\right)_{2}$. Such an outcome is in agreement with observations (from XRD) which show that one of the two $\mathrm{PF}_{6}{ }^{-}$anions does not occupy one single position with equal distances between six $\mathrm{MV} \subset(\mathrm{CBPQT})_{2}$, but is disordered over six symmetry-related positions with one-sixth occupancy.

We have demonstrated that two CBPQT rings are able to encapsulate cooperatively one MV entity to form a mixed-valence 2:1 host-guest complex $\mathrm{MV} \subset(\mathrm{CBPQT})_{2}$. XRD analysis indicates that every three $\mathrm{MV} \subset(\mathrm{CBPQT})_{2}$ share statistically two positive charges to give a body-centered cubic superstructure with the empirical formula of $\left[\mathrm{MV} \subset(\mathrm{CBPQT})_{2}\right]_{3} \bullet\left(\mathrm{PF}_{6}\right)_{2}$. The fact that every $\mathrm{MV} \subset(\mathrm{CBPQT})_{2}$ bears only a mean charge of $2 / 3+$ suggests the distribution of every two positive charges over two $\mathrm{MV}^{\bullet+} \subset\left(\mathrm{CBPQT}^{0}\right)_{2}$ with one neutral $\mathrm{MV}^{0} \subset\left(\mathrm{CBPQT}^{0}\right)_{2}$. Quantum chemistry calculations confirm the mixed-valence state of the solid-state superstructure. This research highlights the potential of host-guest strategies for achieving long-range charge delocalization in solid-state devices by constructing host-guest complexes with precisely adjustable redox states.

\section{ASSOCIATED CONTENT}

\section{Supporting Information}

Detailed information regarding the experimental methods and procedures, X-ray crystallographic data, and supportive figures and tables. This material is available free of charge via the Internet at $h \mathrm{ttp}$ ://pubs.acs.org. CIF file for $\left[\mathrm{MV} \subset(\mathrm{CBPQT})_{2}\right]_{3} \cdot\left(\mathrm{PF}_{6}\right)_{2}$ (CCDC 985866).

\section{AUTHOR INFORMATION}

\section{Corresponding Authors}

zhichang-liu@northwestern.edu

stoddart@northwestern.edu

\section{Notes}

The authors declare no competing financial interests.

\section{ACKNOWLEDGMENT}

This research is part of the Joint Center of Excellence in Integrated Nano-Systems (JCIN) at the King Abdulaziz City for Science and Technology (KACST) and Northwestern University (NU). The authors thank both KACST and NU for their continued support of this research. This research was also supported by the National Science Foundation under grant no. DMR-1710104 (M.R.W.).

\section{REFERENCES}

(1) Winkler, J. R.; Gray, H. B. J. Am. Chem. Soc. 2014, 136, 2930.
(2) McDermott, G.; Prince, S. M.; Freer, A. A.; HawthornthwaiteLawless, A. M.; Papiz, M. Z.; Cogdell, R. J.; Isaacs, N. W. Nature 1995, $374,517$.

(3) Zhu, W.; Zheng, R.; Fu, X.; Fu, H.; Shi, Q.; Zhen, Y.; Dong, H.; Hu, W. Angew. Chem. Int. Ed. 2015, 54, 6785.

(4) Murase, T.; Otsuka, K.; Fujita, M. J. Am. Chem. Soc. 2010, 132,7864 .

(5) Park, J. S.; Karnas, E.; Ohkubo, K.; Chen, P.; Kadish, K. M.; Fukuzumi, S.; Bielawski, C. W.; Hudnall, T. W.; Lynch, V. M.; Sessler, J. L. Science 2010, 329, 1324.

(6) Leblanc, N.; Mercier, N.; Toma, O.; Kassiba, A. H.; Zorina, L.; Auban-Senzier, P.; Pasquier, C. Chem. Commun. 2013, 49, 10272.

(7) Hankache, J.; Wenger, O. S. Chem. Rev. 2011, 111, 5138.

(8) Yoshizawa, M.; Kumazawa, K.; Fujita, M. J. Am. Chem. Soc. 2005, 127, 13456 .

(9) Lindeman, S. V.; Rosokha, S. V.; Sun, D.; Kochi, J. K. J. Am. Chem. Soc. 2002, 124, 843.

(10) Berville, M.; Karmazin, L.; Wytko, J. A.; Weiss, J. Chem. Commun. 2015, 51, 15772 .

(11) Ko, Y. H.; Kim, E.; Hwang, I.; Kim, K. Chem. Commun. 2007, 1305.

(12) Odell, B.; Reddington, M. V.; Slawin, A. M. Z.; Spencer, N.; Stoddart, J. F.; Williams, D. J. Angew. Chem. Int. Ed. 1988, 27, 1547.

(13) Trabolsi, A.; Khashab, N.; Fahrenbach, A. C.; Friedman, D. C.; Colvin, M. T.; Cotí, K. K.; Benítez, D.; Tkatchouk, E.; Olsen, J.-C.; Belowich, M. E.; Carmielli, R.; Khatib, H. A.; Goddard, W. A., III; Wasielewski, M. R.; Stoddart, J. F. Nat. Chem. 2010, 2, 42.

(14) Geraskina, M. R.; Dutton, A. S.; Juetten, M. J.; Wood, S. A.; Winter, A. H. Angew. Chem. Int. Ed. 2017, 56, 9435.

(15) Sakai, F.; Ji, Z.-W.; Liu, J.-H.; Chen, G.-S.; Jiang, M. Chin. Chem. Lett. 2013, 24, 568.

(16) Chen, L.; Zhang, Y.-C.; Wang, W.-K.; Tian, J.; Zhang, L.; Wang, H.; Zhang, D.-W.; Li, Z.-T. Chin. Chem. Lett. 2015, 26, 811.

(17) Li, H.; Zhu, Z.; Fahrenbach, A. C.; Savoie, B. M.; Ke, C.; Barnes, J. C.; Lei, J.; Zhao, Y.-L.; Lilley, L. M.; Marks, T. J.; Ratner, M. A.; Stoddart, J. F. J. Am. Chem. Soc. 2013, 135, 456.

(18) Sun, J.; Liu, Z.; Liu, W.-G.; Wu, Y.; Wang, Y.; Barnes, J. C.; Hermann, K. R.; Goddard, W. A., III; Wasielewski, M. R.; Stoddart, J. F. J. Am. Chem. Soc. 2017, 139, 12704

(19) Frasconi, M.; Fernando, I. R.; Wu, Y.; Liu, Z.; Liu, W.-G.; Dyar, S. M.; Barin, G.; Wasielewski, M. R.; Goddard, W. A., III; Stoddart, J. F. J. Am. Chem. Soc. 2015, 137, 11057

(20) Bockman, T. M.; Kochi, J. K. J. Org. Chem. 1990, 55, 4127.

(21) Porter, W. W.; Vaid, T. P.; Rheingold, A. L. J. Am. Chem. Soc. 2005, 127, 16559.

(22) Ivanov, M. V.; Wang, D.; Navale, T. S.; Lindeman, S. V.; Rathore, R. Angew. Chem. Int. Ed. 2018, 57, 2144.

(23) Fahrenbach, A. C.; Barnes, J. C.; Lanfranchi, D. A.; Li, H.; Coskun, A.; Gassensmith, J. J.; Liu, Z.; Benítez, D.; Trabolsi, A.; Goddard, W. A., III; Elhabiri, M.; Stoddart, J. F. J. Am. Chem. Soc. 2012, 134,3061 .

(24) Turner, M. J.; McKinnon, J. J.; Wolff, S. K.; Grimwood, D. J.; Spackman, P. R.; Jayatilaka, D.; Spackman, M. A. CrystalExplorer 17; University of Western Australia, 2017. 
Insert Table of Contents artwork here

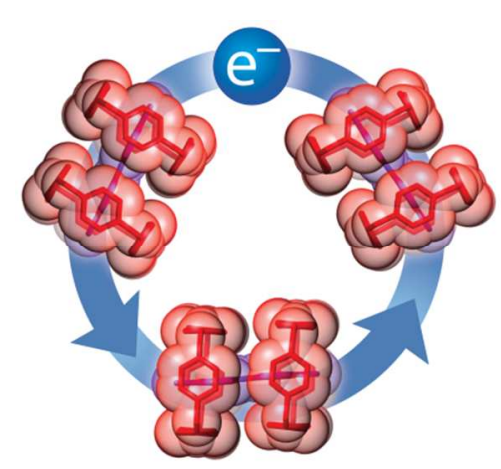
8

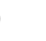

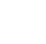
25 7

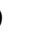

.

.

2

